\title{
A balança comercial é uma restrição ao crescimento econômico dos estados brasileiros? Uma análise para o período de 1991 a 2009
}

\author{
Is the balance of payments a restriction to the economic growth of \\ Brazilian states? An analysis for the 1991-2009 period
}

FELIPE DE SOUSA BASTOS
GUILHERME IRFFI
IVAN CASTELAR*

RESUMO: Este trabalho investiga se há de fato uma restrição imposta pelo balanço de pagamentos - via relação entre as elasticidades-renda das importações e das exportações sobre o crescimento econômico dos estados brasileiros. Em outros termos, verifica-se a validade da Lei de Thirlwall para a economia dos estados brasileiros no período de 1991 a 2009. Para tanto, estima-se as referidas elasticidades por meio do estimador para painéis dinâmicos System-GMM, que contorna, além dos problemas clássicos de estimação, o viés de endogeneidade do painel dinâmico. Os resultados apontam para a validade da lei, visto que a elasticidade-renda das importações mostrou-se superior à elasticidade-renda das exportações. PALAVRAS-CHAVE: Lei de Thirlwall; Crescimento Econômico; Estados Brasileiros.

ABSTRACT: This paper investigates whether there is a restriction imposed by the balance of payments - through the relationship between income elasticities of imports and exports - on the economic growth of Brazilian states. In other words, it checks the validity of Thirlwall's Law to the Brazilian states in the period from 1991 to 2009. These elasticities were estimated using the dynamic panel estimator System-GMM, which circumvents the classical endogeneity problem inherent to dynamic panels. The results point out to the validity of the law, since the income elasticity of imports was higher than the income elasticity of exports. KEYWORDS: Thirlwall's Law; Economic Growth; Brazilian states.

JEL Classification: E12; F00; C01.

\footnotetext{
* Respectivamente, Doutorando em Economia - Centro de Aperfeiçoamento de Economistas do Nordeste da Universidade Federal do Ceará - CAEN/UFC, E-mail: flpsbastos@gmail.com; Professor Adjunto do Departamento de Economia Aplicada da Universidade Federal do Ceará - DEA/UFC, E-mail: ghidirffi@gmail.com; Professor Titular da Universidade Federal do Ceará, email: lume1250@ yahoo.com.br. Submetido: 23/Janeiro/2015: Aprovado: 24/Fevereiro/2016.
} 


\section{INTRODUÇÃO}

O modelo de desenvolvimento econômico proposto por Thirlwall (1979) segue uma abordagem pós-keynesiana ao enfatizar o papel da demanda e reserva um papel fundamental às restrições externas sobre o crescimento econômico.

McCombie e Thirlwall (1994) também utilizam uma abordagem dos determinantes do produto sob a ótica da demanda. Estes autores adotam um modelo de crescimento econômico que considera restrições sobre o balanço de pagamentos, advindas de uma certa combinação de elasticidades-renda. Neste contexto, as causas para as diferenças nas taxas de crescimento de longo prazo entre os países estariam ligadas às diferenças nas taxas de crescimento da demanda de cada um deles.

Sob esta perspectiva, a restrição externa tem importância fundamental no crescimento de países, estados e regiões que apresentam uma relação desfavorável entre as elasticidades-renda da demanda por importações e por exportações, mesmo com mudanças significativas na pauta de exportações devido a uma maior participação de produtos mais intensivos em tecnologia.

Dessa forma, este trabalho investiga se há de fato uma restrição imposta pelo balanço de pagamentos - via relação entre as elasticidades-renda de importações e exportações - sobre o crescimento econômico dos estados brasileiros ${ }^{1}$ ao longo do período que vai de 1991 a 2009.

Cabe ressaltar que, nesse período, a economia brasileira pode ser caracterizada pela estabilização macroeconômica, com aumento da renda e da demanda por trabalho; entretanto, não se pode dizer que a economia gozava de pleno emprego. Por isso, optou-se por testar o pressuposto da Lei de Thirlwall de que o crescimento econômico é conduzido pela demanda ao invés da oferta ${ }^{2}$, como preconiza a teoria neoclássica do crescimento econômico que tem como determinantes a acumulação de estoques de capital, físico e humano, além da tecnologia e de outros fatores ligados à oferta ${ }^{3}$.

Para testar se a Lei de Thirlwall para os estados brasileiros, isto é, verificar se o crescimento econômico dos estados brasileiros pode ser restrito por desequilíbrios no balanço de pagamentos, caso a elasticidade-renda das importações supere a elasticidade-renda das exportações, são estimadas duas equações de demanda por meio do estimador para painéis dinâmicos System-GMM - desenvolvido por

\footnotetext{
${ }^{1}$ Sem perda de generalidade, optou-se por denominar as Unidades da Federação, os 26 Estados mais o Distrito Federal, como estados brasileiros.

${ }^{2}$ Abordagem adotada por Arruda et al. (2013) para estudar os efeitos do comércio internacional sobre o crescimento econômico dos estados brasileiros na perspectiva neoclássica.

${ }^{3}$ Vale ressaltar que não se utiliza do pressuposto do modelo neoclássico (pleno emprego contínuo e global) e, por isso, não prediz que o crescimento econômico de longo prazo é determinado de maneira exógena pelo progresso técnico e pelo aumento da força de trabalho.
} 
Arellano e Bond (1991), Arellano e Bover (1995) e Blundell e Bond (1998) - das quais se extrai as elasticidades-renda de importações e exportações.

Mais especificamente, verifica-se a hipótese de que a elasticidade-renda das importações representa uma restrição ao crescimento dos estados brasileiros, enquanto a elasticidade-renda das exportações atenua a restrição imposta pelas importações.

Deste modo, caso tal hipótese seja aceita, a relação entre o comércio internacional e o crescimento econômico dos estados brasileiros pode ser influenciada pela ótica da demanda, o que deve ser levado em conta na adoção de políticas de desenvolvimento econômico para os estados e macrorregiões brasileiras.

Além desta introdução, este trabalho está dividido em mais cinco seções. A próxima seção descreve o modelo proposto por Thirlwall, além de algumas das suas aplicações empíricas para a economia brasileira. Nas terceira e quarta seções são feitas a descrição dos dados e a metodologia econométrica empregada. Em seguida, na quinta seção, são reportados e analisados os resultados. E, por fim, são tecidas as considerações finais.

\section{MODELO TEÓRICO DE THIRLWALL E AS APLICAÇÕES EMPÍRICAS}

O modelo de crescimento restrito pelo balanço de pagamentos de Thirlwall é muitas vezes chamado de multiplicador dinâmico de comércio de Harrod, por ser derivado do multiplicador de comércio estático de Harrod, o qual considera uma economia aberta, sem poupança, investimento e governo; e, tem como multiplicador $1 / m$, sendo $m$ a propensão marginal a importar.

O trabalho de Thirlwall (1979) postula que os países crescem a taxas distintas em função de terem elasticidades-renda das importações e exportações diferentes. Isto é, o autor propõe um modelo de crescimento que tem o balanço de pagamentos como restrição, condicionando esta restrição às diferenças nas taxas de crescimento internacional da renda. Tal limitação externa é obtida através do seguinte modelo ${ }^{4}$ :

$$
\begin{gathered}
X=\left(P / P^{*}\right)^{z}\left(Y^{*}\right)^{\varepsilon_{X, Y^{*}}} \\
M=\left(P / P^{*}\right)^{\mu} Y^{\varepsilon_{M, Y}}
\end{gathered}
$$

Sendo $X$ a demanda por exportações, $M$ a demanda por importações, $Y$ a renda interna, enquanto $Y^{*}$ é a renda do resto do mundo, $\left(P / P^{*}\right)$ a razão entre os preços domésticos e externos, $\varepsilon_{X, Y^{*}}$ é a elasticidade-renda do resto do mundo para as exportações, $\varepsilon_{M, Y}$, a elasticidade-renda da demanda de importações, $\mathrm{z}$, a elasti-

\footnotetext{
${ }^{4}$ Baseado em Davidson (1990).
} 
cidade-preço da demanda para as exportações e $\mu$, a elasticidade-preço para as importações. Tomando o logaritmo natural em (1) e (2) e ignorando o efeito-substituição, chega-se ao crescimento da renda doméstica compatível com um balanço de pagamentos estável; ou seja,

$$
y=x / \varepsilon_{M, Y}
$$

em que $y$ é a taxa de crescimento da renda e $x$, a taxa de crescimento das exportações.

$\mathrm{O}$ crescimento das exportações - novamente ignorando o efeito-substituição - tem a seguinte forma:

$$
x=\varepsilon_{X, Y^{*}} y^{*}
$$

em que $y^{*}$ é a taxa de crescimento da renda internacional. A equação (3) pode, então, ser reescrita como,

$$
y=\left(\varepsilon_{X, Y^{*}} y^{*}\right) / \varepsilon_{M, Y}
$$

Logo, neste modelo, a taxa de crescimento de um país depende do crescimento da renda do resto do mundo e das elasticidades-renda de exportações e importações. Adicionalmente, rearranjando a última equação, tem-se que,

$$
y / y=\varepsilon_{X, Y^{*}} / \varepsilon_{M, Y}
$$

Assim, a razão entre o crescimento da renda doméstica e a renda do resto mundo é igual à razão entre as elasticidades-renda de exportações e importações. Portanto, se, por exemplo, $\varepsilon_{X, Y^{*}} / \varepsilon_{M, Y}<1$, o crescimento da renda doméstica será limitado pela necessidade de manter o equilíbrio do balanço de pagamentos e o país crescerá a uma taxa inferior àquela do resto do mundo.

Este modelo foi usado por Thirlwall para tentar elucidar por que o Reino Unido apresentou menor crescimento do que a média mundial no período 1953-1976. Sendo assim, a sua abordagem se propõe a explicar as diferentes taxas de crescimento observadas empiricamente, além de fornecer outra explicação que não esteja correlacionada com a taxa de poupança dos países ou mesmo com a distância em que eles estejam de seu estado estacionário.

De modo geral, pode-se dizer que este modelo privilegia a importância da balança comercial sobre o crescimento econômico dos países. Percebe-se, então, que este modelo difere daquele proposto por Solow, o qual assume uma função de produção neoclássica ${ }^{5}$ e postula que as economias tendem a convergir para um

\footnotetext{
${ }^{5}$ Isto é, homogênea de grau 1 e com produtividade marginal dos fatores de produção positiva e decrescente.
} 
estado estacionário estável. Desse modo, tem-se que uma das principais diferenças entre estas duas abordagens consiste no fato de Thirlwall introduzir o balanço de pagamentos como restrição ao crescimento dos países.

Para obter diretamente a estimativa da elasticidade-renda do resto do mundo das exportações $\left(\varepsilon_{X, Y^{*}}\right)$ e da elasticidade-renda interna das importações $\left(\varepsilon_{M, Y}\right)$, ambas as equações ${ }^{6}$ são estimadas em sua versão logarítmica.

Deste modo, o balanço de pagamentos representará uma restrição ao crescimento econômico dos estados brasileiros se $\varepsilon_{M, Y}>\varepsilon_{X, Y^{*}}$, visto que, nesta situação, as importações crescerão mais rapidamente do que as exportações para aumentos de mesma proporção na renda interna e do resto do mundo.

A escolha por esta modelagem para aferir a relação entre abertura comercial e crescimento econômico da economia brasileira decorre do fato de se observar que, em diversas pesquisas empíricas, há uma forte evidência da validade da Lei de Thirlwall para países latino-americanos, uma vez que o crescimento econômico desses países está condicionado por esta relação de longo prazo.

Ao utilizar o modelo desenvolvido por Thirlwall (1979) para verificar empiricamente a relação entre o comércio internacional e o crescimento econômico da América Latina e do Caribe no período recente, Martini (2010) observou que embora a elasticidade-renda das importações tenha permanecido constante nas últimas décadas, houve uma tendência autônoma de elevação da demanda por importações na região. Além disso, a taxa de crescimento da América Latina e Caribe compatível com o equilíbrio na balança comercial apenas beira os $3 \%$ anuais, taxa que é considerada excessivamente baixa para que esses países possam superar suas condições de subdesenvolvimento.

Sob outra perspectiva, Nakabashi (2010) apresenta uma tentativa de agregar ambas as teorias de crescimento, abordagem clássica (oferta) e a keynesiana (demanda). Para tanto, considera a possibilidade da restrição imposta pelo balanço de pagamentos afetar indiretamente o crescimento da renda por meio de seu efeito sobre a acumulação de capital físico e humano.

O Quadro 1 sintetiza alguns resultados da literatura a respeito da validade da Lei de Thirlwall. Além disso, verifica-se que com exceção de Da Silva, Vergolino e Lima $(2000)^{7}$ e Maia e Nunes $(2006)^{8}$, os demais trabalhos atestam a validade da Lei de Thirlwall. Com esteio nessa revisão, pode-se dizer que esta pesquisa tende a contribuir com a literatura pela estratégia empírica a ser adotada, uma vez que se estimam duas equações de demandas dinâmicas, uma para as exportações e outra para as importações, através do método System-GMM, descrito em mais detalhes na quarta seção.

\footnotetext{
${ }^{6}$ Explicitadas na seção de metodologia econométrica.

${ }^{7}$ Os autores analisam a relação entre o PIB e as exportações para a economia brasileira no período de 1952 a 1998. No entanto, não consideram outras variáveis que, possivelmente, afetaram tanto as exportações quanto o PIB como, por exemplo, os choques no preço do petróleo (1973 e 1979).

${ }^{8}$ Considerando o subperíodo 1999:1-2005:3, obtêm $\varepsilon_{M, Y}<\varepsilon_{X, Y^{*}}$
} 
Quadro 1: Evidências de Validade da Lei de Thirlwall

\begin{tabular}{|c|c|c|c|c|}
\hline Autores & Período & País & Metodologia & $\varepsilon_{M, Y}>\varepsilon_{X, Y^{*}}$ \\
\hline $\begin{array}{c}\text { Da Silva, } \\
\text { Vergolino e } \\
\text { Lima (2000) }\end{array}$ & 1952-1998 & Brasil & $\begin{array}{c}\text { Teste de } \\
\text { Causalidade de } \\
\text { Engle-Granger, Teste } \\
\text { de Cointegração de } \\
\text { Johansen }\end{array}$ & Não \\
\hline $\begin{array}{l}\text { Holland, Vieira e } \\
\text { Canuto (2004) }\end{array}$ & $1950-2000$ & América Latina & VAR & Sim \\
\hline $\begin{array}{c}\text { Maia e Nunes } \\
\qquad(2006)\end{array}$ & 1990-2004 & Brasil & MOO & Sim/Não* \\
\hline $\begin{array}{c}\text { Esteves e } \\
\text { Correia (2010) }\end{array}$ & 1980-2005 & $\begin{array}{c}\text { Latino-americanos: } \\
\text { Argentina, Brasil, } \\
\text { Chile, Colômbia e } \\
\text { México }\end{array}$ & $\begin{array}{c}\text { Teste de Causalidade } \\
\text { de Engle-Granger }\end{array}$ & Sim \\
\hline Martini (2010) & 1980-2005 & $\begin{array}{c}30 \text { países da } \\
\text { América Latina e } \\
\text { Caribe, com exceção } \\
\text { de Cuba e Barbados }\end{array}$ & $\begin{array}{c}\text { Métodos para } \\
\text { Dados em Painel: } \\
\text { MQO empilhados, } \\
\text { Primeiras Diferenças } \\
\text { e Efeitos Fixos }\end{array}$ & Sim \\
\hline Nakabashi (2010) & $1947-2008$ & Brasil & $\begin{array}{c}\text { MOO e Iteratively } \\
\text { Reweighted Least } \\
\text { Squares (IRLS) }\end{array}$ & Sim \\
\hline
\end{tabular}

Fonte: Elaborado pelos autores.

Nota: * Porém, obtêm para o subperíodo 1999:1-2005:3.

\section{DESCRIÇÃO E ANÁLISE DOS DADOS}

Para aferir a validade da Lei de Thirlwall, foram coletadas informações anuais em nível estadual, considerando o período entre 1991 e 2009 para os 26 estados e o Distrito Federal, denominados como estados brasileiros. Enquanto a variável que capta a renda do resto do mundo foi construída a partir de uma adaptação da modelagem proposta por Pesaran, Schuermann e Weiner (2004).

Primeiramente, ordenaram-se os países que absorvem o maior montante das exportações de cada um dos estados brasileiros a cada ano. A partir daí, selecionou-se os 5 principais parceiros comerciais anualmente ${ }^{9}$ para cada estado; obten-

\footnotetext{
${ }^{9}$ Optou-se pela seleção anual dos 5 principais parceiros comerciais por conta da parcela significante de comércio atribuída a eles e devido à escassez de informações de renda de muitos países, o que tornaria a construção da variável para mais de 5 países tarefa muito difícil. Em algumas situações, a rubrica apareceu entre os principais parceiros comerciais, como se trata de uma observação composta pelas importações de muitos países indefinidos e que provavelmente mudam ao longo do tempo (de modo que não é possível obter a renda doméstica referente a esta rubrica), substituiu-se pelo país subsequente sempre que esta apareceu no ranking .
} 
do-se, desse modo, pesos que definem a importância relativa dos países para as exportações dos estados brasileiros. Neste contexto, a equação que define a renda do resto do mundo tem a forma:

$$
Y_{i t}^{*}=\sum_{j=1}^{5} \alpha_{i j t} Y_{j t}^{*}, \quad t=1991,1992, \ldots, 2009 ; i=1,2, \ldots .27
$$

em que, $Y_{j t}^{*}$, é a renda do país $j$ no ano $t \mathrm{e}, \alpha_{i j t}=X_{i j t} / \sum_{j=1}^{5} X_{i j t}$, refere-se à razão entre o montante exportado pelo estado $i$ para o país $j$ no ano $t$; sendo, portanto, o peso da renda do país $j$ para o estado $i$ no ano $t$. Supõe-se que estes países exaurem todo o fluxo de exportações de cada um dos estados brasileiros a cada ano, isto é, $\sum_{j=1}^{5} \alpha_{i j t}=1$ para $t=1991,1992, \ldots, 2009$ e $i=1,2 \ldots, 27$.

Cabe destacar que, apesar de não exaurir todo o fluxo de exportação dos estados brasileiros ${ }^{10}$, como pressuposto, a proxy aqui construída apresenta um substancial ganho quando comparada ao Produto Interno Bruto dos EUA, utilizado como proxy para a renda mundial em alguns estudos ${ }^{11}$, nos quais atribui-se implicitamente peso 1 ao fluxo de exportações com este país, ignorando completamente o montante absorvido pelas demais economias.

Feitas essas considerações, optou-se por construir um ranking dos principais parceiros comerciais para todos os estados brasileiros (Quadro 2). Diante da grande variabilidade dos países que tiveram maior representatividade como destino das exportações brasileiras ao longo do período amostral, optou-se por apresentar os países que mais vezes estiveram presentes entre os 5 principais parceiros comerciais de cada estado a cada ano.

Note que, com exceção de Mato Grosso, Mato Grosso do Sul e Roraima, a economia norte-americana está em todos os demais rankings, o que faz deste país um dos principais parceiros comerciais no período em questão.

O Quadro 3 apresenta uma síntese das variáveis utilizadas neste estudo, bem como suas proxies, fontes e os respectivos sinais esperados. Note que, tanto as observações de exportação e importação dos estados brasileiros foram coletadas junto ao MDIC/SECEX. A renda interna, aferida a partir do PIB dos estados, tem como fonte o IBGE, e espera-se que impacte positivamente as importações dos Estados.

Para o cálculo da renda do resto do mundo, foram utilizadas as informações do MDIC/SECEX para fazer o ranking, ao passo que o PIB dos países tem como fonte o Banco Mundial. Vale ressaltar que a renda dos países utilizada na constru-

${ }^{10}$ É importante ressaltar que as informações de exportação dos estados brasileiros fornecidas pelo sistema Aliceweb são registradas de acordo com o estado em que foi produzida, independentemente da localização da empresa exportadora. Já as informações sobre o volume importado são creditadas de acordo com o domicílio fiscal da empresa importadora, independentemente do ponto onde a mercadoria entrou em território nacional.

${ }^{11}$ Arienti e Campos (2002) e Nakabashi (2012), por exemplo. 
Quadro 2: Principais parceiros comerciais por estado entre 1991-2009

\begin{tabular}{|c|c|}
\hline Estados Brasileiros & País \\
\hline Acre & Estados Unidos, Reino Unido, Bolívia, China, Argentina \\
\hline Alagoas & Estados Unidos, Rússia, Japão, Marrocos, Canadá \\
\hline Amapá & Japão, Estados Unidos, Suécia, Venezuela, Noruega \\
\hline Amazonas & Estados Unidos, Argentina, Colômbia, Venezuela, Alemanha \\
\hline Bahia & Argentina, Estados Unidos, Holanda, Japão, Bélgica, México \\
\hline Ceará & Estados Unidos, Argentina, Canadá, Holanda, Itália, Japão \\
\hline Distrito Federal & $\begin{array}{l}\text { Estados Unidos, Holanda, Emirados Árabes Unidos, Venezuela, } \\
\text { Portugal, Rússia, Arábia Saudita }\end{array}$ \\
\hline Espírito Santo & Estados Unidos, Coreia do Sul, Itália, Bélgica, China \\
\hline Goiás & Holanda, Estados Unidos, Alemanha, Japão, China \\
\hline Maranhão & Estados Unidos, Holanda, Bélgica, Argentina, Japão \\
\hline Mato Grosso & Holanda, China, Alemanha, Espanha, Itália \\
\hline Mato Grosso do Sul & Holanda, Argentina, França, Alemanha, China \\
\hline Minas Gerais & Alemanha, Estados Unidos, Japão, Argentina, Itália \\
\hline Pará & Estados Unidos, Japão, Bélgica, Alemanha, França \\
\hline Paraíba & Estados Unidos, Holanda, Argentina, Japão, Espanha \\
\hline Paraná & Estados Unidos, Holanda, Argentina, China, Alemanha \\
\hline Pernambuco & Estados Unidos, Argentina, Holanda, Rússia, Nigéria \\
\hline Piauí & Estados Unidos, Espanha, Alemanha, Itália, Japão \\
\hline Rio de Janeiro & Estados Unidos, Chile, Argentina, China, México \\
\hline Rio Grande do Norte & Estados Unidos, Reino Unido, Holanda, França, Espanha, Nigéria \\
\hline Rio Grande do Sul & Estados Unidos, Argentina, China, Alemanha, Reino Unido \\
\hline Rondônia & Estados Unidos, Itália, Hong Kong, Reino Unido, China \\
\hline Roraima & Venezuela, Bélgica, Holanda, China, Suíça \\
\hline Santa Catarina & Estados Unidos, Alemanha, Argentina, Reino Unido, Japão \\
\hline São Paulo & Estados Unidos, Argentina, México, Holanda, Chile \\
\hline Sergipe & Holanda, Estados Unidos, Argentina, Paraguai, Espanha \\
\hline Tocantins & China, Estados Unidos, Argentina, Portugal, Espanha, Hong Kong \\
\hline
\end{tabular}

Fonte: Elaborado pelos autores a partir de informações do MDIC/SECEX.

Nota: A seleção dos principais parceiros comerciais foi feita a partir de um ranking entre os países que mais apareceram entre os 5 principais parceiros comerciais a cada ano. 
ção da proxy para a renda do resto do mundo foram devidamente deflacionadas pelo Índice de Preços por Atacado (IPA) dos Estados Unidos, obtido junto ao Fundo Monetário Internacional (FMI), tendo 2000 como ano-base.

Quadro 3: Resumo descritivo das Variáveis

\begin{tabular}{|c|c|c|c|}
\hline Variável & Proxy & Fonte & Sinal Esperado \\
\hline Exportações1 $\left(X_{i t}\right)$ & Exportação & MDIC/SECEX & Var. Dependente \\
\hline Importações $\left(M_{i t}\right)$ & Importação & MDIC/SECEX & Var. Dependente \\
\hline $\begin{array}{c}\text { Renda Interna }\left(Y_{i t}\right) \\
\text { Renda do Resto } \\
\text { do Mundo }\left(Y_{i t}^{*}\right)\end{array}$ & Produto Interno Bruto (PIB) & IBGE & + \\
\hline
\end{tabular}

Fonte: Elaborado pelos autores.

A composição média das pautas de exportações e importações brasileiras ${ }^{12}$, no período de 1991 a 2009, são dominadas por produtos manufaturados com participação da ordem de $78,69 \%$ e $52,06 \%$, respectivamente, como se observa no Gráfico 1. Em seguida, têm-se os produtos básicos como mais representativos em ambas as pautas.

Apesar da grande representatividade dos manufaturados nas pautas de importação e exportação, o fluxo de comércio como um todo representou, em média, apenas $10,5 \%$ do PIB brasileiro no período em questão. Além disso, observa-se, pelo Gráfico 2, que houve uma evolução da participação do comércio exterior no PIB durante o período de 1991 a 2008, com uma queda em 2009.

\footnotetext{
${ }^{12}$ Segundo SECEX/MDIC, a composição da pauta de importação e exportação é classificada e definida da seguinte forma: a) Produtos básicos: produtos de baixo valor, normalmente intensivo em mão de obra, cuja cadeia produtiva é simples e que sofrem poucas transformações; por exemplo, minério de ferro, grãos, agricultura etc. b) Produtos industrializados: dividem-se em semimanufaturados e manufaturados, mais uma vez considerando o grau de transformação. b.1) semimanufaturados produto que passou por alguma transformação, ex: suco de laranja congelado; couro. b.2) manufaturado - produto normalmente de maior tecnologia, com alto valor agregado, ex: televisor, chip de computador, automóvel, CD com programa de computador etc. Já as operações especiais referem-se a transações em que é impossível identificar o código do produto, por exemplo, ouro não monetário, bens militares, água, gás e eletricidade, arrendamentos financeiros, zonas de livre comércio e áreas especiais alfandegárias.
} 
Gráfico 1: Composição Média do Fluxo Comercial Brasileiro em 1991-2009.

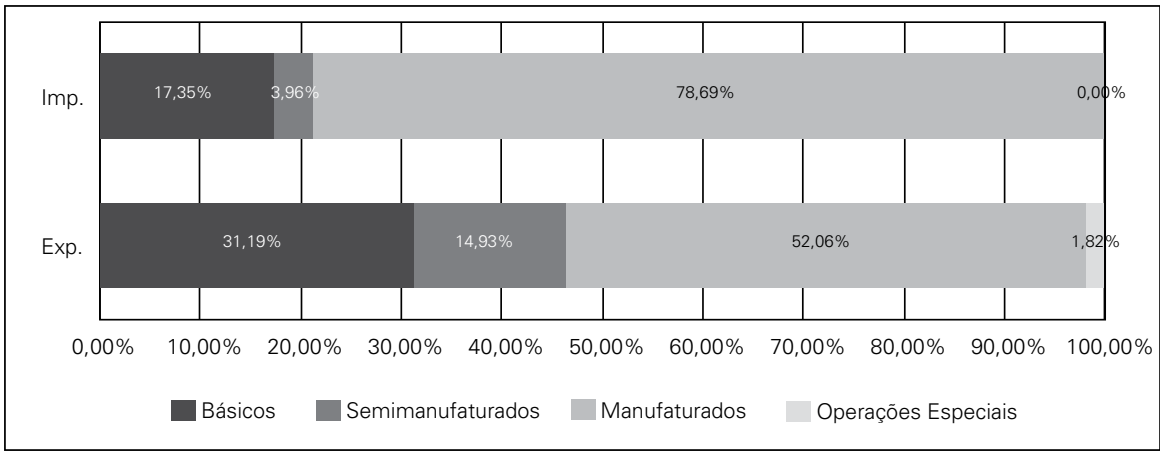

Fonte: Elaborado pelos autores a partir de dados do MDIC/SECEX.

Deve-se ressaltar que o crescimento acelerado nos anos anteriores a 2008 foi devido a um boom nos preços internacionais das commodities, ao passo que a retração verificada a partir desse ano pode ser consequência da crise financeira mundial; a qual, segundo Ferraz (2013), transmite-se para a economia brasileira através de uma aguda redução no volume internacional de comércio, queda nos preços internacionais das commodities e fuga dos capitais de curto prazo.

Gráfico 2: Evolução da participação do Comércio Exterior no PIB Brasileiro ${ }^{13}$.

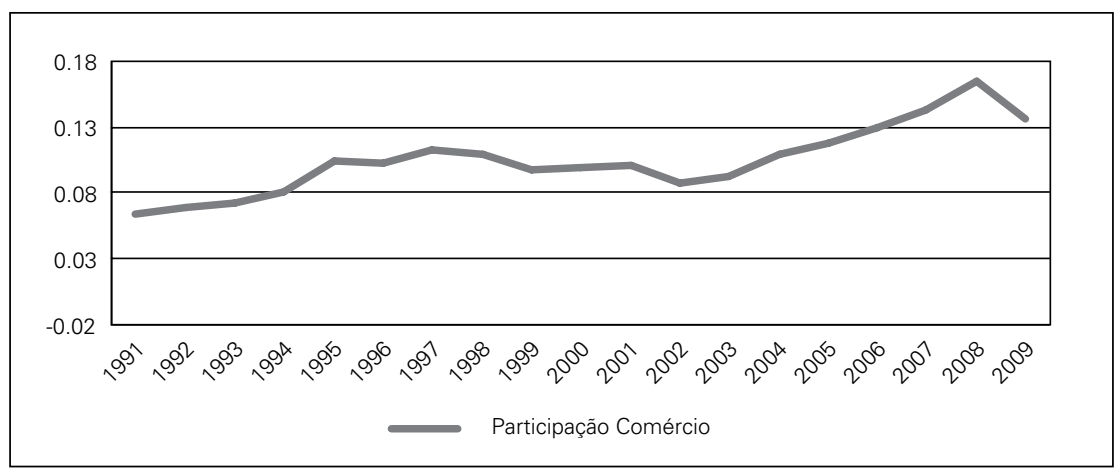

Fonte: Elaborado pelos autores a partir de dados do MDIC/SECEX/IBGE.

\section{METODOLOGIA ECONOMÉTRICA}

Para investigar se a balança comercial representa, de fato, uma restrição ao crescimento econômico dos estados brasileiros, necessita-se de estimações das

${ }^{13}$ Razão entre a soma (Exportações + Importações) pelo PIB. 
elasticidades-renda de exportações e importações, $\varepsilon_{X, Y^{*}}$ e $\varepsilon_{M, Y}$, reportadas pelos coeficientes $\beta_{1}$ e $\gamma_{1}$ nas equações (8) e (9), respectivamente ${ }^{14}$ :

$$
\begin{aligned}
& x_{i t}=\beta_{0} x_{i t-1}+\beta_{1} y_{i t}^{*}+\varepsilon_{i t} \\
& m_{i t}=y_{0} m_{i t-1}+\gamma_{1} y_{i t}+v_{i t}
\end{aligned}
$$

Sendo que $x_{i t}$ e $m_{i t}$ representam, respectivamente, o logaritmo das exportações e importações; $x_{i t-1}$ e $m_{i t-1}$ definem o logaritmo dos níveis de exportação e importação do período anterior, com o intuito de refletir um efeito transferência das exportações (importações) passadas para a futura; enquanto $y_{i t}^{*}$ e $y_{i t}$ denotam a renda mundial e a renda interna. Por fim, $\varepsilon_{i t}$ e $v_{i t}$ são os termos de erros, enquanto os subscritos $i$ e $t$ referem-se ao estado $i$ no ano $t$.

A presença das variáveis dependentes defasadas como variável explicativa caracteriza o modelo de painel dinâmico. Em modelos assim especificados, haverá problema de endogeneidade ${ }^{15}$, em consequência da presença das variáveis explicativas $x_{i t-1}$ e $m_{i t-1}$ gerando um viés no painel dinâmico. Logo, as estimativas de MQO tendem a ser enviesadas e inconsistentes, superestimando o coeficiente da variável dependente defasada. Este viés não é corrigido nem mesmo com o uso do estimador de efeito fixo Within-groups.

Para controlar o problema de endogeneidade, pode-se aplicar a transformação do modelo em primeira diferença e proceder à estimação por $G M M$, método que minimiza as condições de momentos da distribuição, conhecido como Difference-GMM. Deste modo, as equações (8) e (9) são reescritas como:

$$
\begin{aligned}
& \Delta x_{i t}=\beta_{0} \Delta x_{i t-1}+\beta_{1} \Delta y_{i t}^{*}+\Delta \varepsilon_{i t} \\
& \Delta m_{i t}=\gamma_{0} \Delta m_{i t-1}+\gamma_{1} \Delta y_{i t}+\Delta v_{i t}
\end{aligned}
$$

No entanto, além do problema adicional de autocorrelação dos erros devido à transformação em primeira diferença, a endogeneidade ainda persiste, pois $\Delta x_{i t-1}$ e $\Delta m_{i t-1}$ são correlacionados com $\Delta \varepsilon_{i t}$ e $\Delta v_{i t}$, respectivamente.

É necessário, então, o uso de um instrumento que expurgue completamente a endogeneidade do modelo. Das hipóteses assumidas para o método de estimação $G M M^{16}$, sabe-se, que $E\left(\Delta x_{i t-\mathrm{s}} \Delta \varepsilon_{i t}\right)=0$ e $E\left(\Delta m_{i t-\mathrm{s}} \Delta v_{i t}\right)=0$ para $t=3,4, \ldots$, T e $s \geq 2$.

\footnotetext{
${ }^{14}$ Perceba que nas estimações das equações (8) e (9) pressupõe-se implicitamente que não há diferenças nos níveis de preço entre os estados brasileiros.

${ }^{15}$ Caso em que as variáveis explicativas do modelo são correlacionadas com os resíduos $E\left(Z_{i t}, \varepsilon_{i t}\right) \neq 0$. Uma variável qualquer pode ser classificada como: estritamente exógena, se não é correlacionada com os termos de erro passados, presente e futuros; fracamente exógena, se é correlacionada apenas com valores passados do termo de erro; e endógena, se é correlacionada com os termos de erro passados, presente e futuros.

${ }^{16}$ Para uma descrição detalhada das hipóteses e de todo o processo de estimação do GMM ver Roodman (2009) e Arruda et al. (2013).
} 
Logo, Arellano e Bond (1991) sugerem utilizar a primeira diferença de $x_{i t-1}$ e $m_{i t-1}$ com defasagens maiores do que 1 , como instrumentos para expurgar a endogeneidade. Entretanto, para painéis com dimensão temporal pequena, os instrumentos utilizados podem ser fracos e o problema de endogeneidade persistirá.

Desse modo, Arellano e Bover (1995) e Blundell e Bond (1998) sugerem a composição de um sistema que combine (8) e (10), e (9) e (11), utilizando como instrumento as variáveis em primeira diferença defasadas para a equação em nível e as variáveis em nível defasadas para a equação em primeira diferença. Surge, então, o método de estimação que ficou conhecido como System-GMM.

Neste artigo emprega-se o System-GMM e, seguindo Roodman (2009), reportam-se todas as escolhas de especificação do modelo. Há duas técnicas de estimação GMM para o System-GMM, uma em que se supõe que os resíduos sejam esfé$\operatorname{ricos}^{17}$ (one-step), e outra, two-step, na qual se utilizam os resíduos gerados na primeira estimação para obter uma estimativa consistente da matriz de variância-covariância.

Devido ao pequeno tamanho da amostra, utiliza-se a variante two-step para a estimação do painel. No entanto, essa variante tende a subestimar os erros-padrão, sendo necessário utilizar a correção de Windmeijer (2005) para amostras finitas, tornando a estimação two-step mais robusta.

Como o painel dinâmico é sensível à autocorrelação dos erros, aplica-se o teste de Arellano e Bond para autocorrelação de primeira e segunda ordem, e para que a estimação seja consistente, deve-se rejeitar a hipótese nula de ausência de autocorrelação de primeira ordem e não rejeitar a hipótese de autocorrelação de segunda ordem.

Ademais, é preciso definir critérios para a quantidade e validade dos instrumentos utilizados. Primeiramente, para que não haja sobreidentificação ${ }^{18}$, recomenda-se a restrição de que o número de instrumentos deva ser menor ou igual ao número de grupos investigados (neste caso, 26 Estados e o Distrito Federal).

Para testar a validade dos instrumentos, adotam-se as estatísticas de teste de Hansen (1982) e Sargan (1958), ${ }^{19}$ que têm a validade dos instrumentos como hipótese nula. Além disso, é importante notar que estes testes possuem baixo poder se o modelo inclui uma ampla seleção de instrumentos. Por esse motivo, também se analisa o teste de exogeneidade de grupos particulares de instrumentos, o teste difference-Hansen definido como a diferença entre a estatística de Hansen, obtida com um número menor de instrumentos, exclusive os instrumentos inválidos, e a

\footnotetext{
${ }^{17}$ Homocedásticos.

18 Caso em que o número de instrumentos é superior ao número de grupos. Para mais detalhes, ver Roodman (2009). No presente estudo, o número de grupos é dado pela quantidade de estados presentes no painel.

${ }^{19}$ A estatística de teste de Hansen (1982) é ainda robusta na presença de heterocedasticidade, enquanto a estatística de Sargan torna-se inconsistente. Vale destacar que o teste de Sargan (1958) é um caso especial da estatística J de Hansen para o caso de homocedasticidade.
} 
equação com todos os instrumentos. A hipótese nula é a de que ambos os grupos de instrumentos são válidos.

Por fim, visto que os estimadores de MQO e Within-groups, respectivamente, superestimam e subestimam o coeficiente das variáveis dependentes defasadas, procede-se à estimação das equações (8) e (9) por ambos os métodos, a fim de verificar se a estimação System-GMM não é enviesada. Para isso, é necessário que os coeficientes estimados por System-GMM pertençam ao intervalo entre os coeficientes estimados por MQO e Within-groups.

\section{ANÁLISE E DISCUSSÃO DOS RESULTADOS}

Esta seção contempla a análise e discussão dos resultados, apresentados na Tabela 1. Observe que os coeficientes estimados pelo método System-GMM, tanto para importações quanto exportações defasadas em um período, encontram-se exatamente dentro dos limites das estimações MQO e Within-groups, fato que atesta a eliminação do viés do painel dinâmico. Como o teste de Arellano-Bond rejeita a nula de ausência de autocorrelação de primeira ordem, mas não rejeita a hipótese nula de ausência autocorrelação de segunda ordem em ambas as estimações, pode-se inferir que as estimações são consistentes.

A partir dos testes de Hansen e Sargan, que não rejeitam a nula, verifica-se a validade dos instrumentos, enquanto o teste Difference-Hansen não rejeita a hipótese de validade de subconjuntos de instrumentos. Diante desses resultados, pode-se, portanto, constatar a robustez das estimações.

No caso das exportações dos estados brasileiros, verifica-se que tanto as exportações defasadas em um período quanto a renda do resto mundo afetam positivamente o crescimento das exportações dos estados brasileiros. Note ainda que em termos de magnitude, o efeito renda é inferior ao da exportação defasada. Sendo que, no caso de crescimento econômico dos países parceiros dos estados exportadores, verifica-se que um aumento de $10 \%$ na renda deles tende a aumentar, em média, 2,7650\% das exportações dos estados brasileiros.

Em relação às importações, também se observa um efeito positivo tanto das importações defasadas em um período quanto da renda dos estados brasileiros. Em termos de magnitude, o efeito das importações do ano anterior é superior ao efeito renda interna. No caso de crescimento econômico dos estados, pode-se dizer que as importações de bens e serviços respondem positivamente, porém de forma inelástica, pois caso o crescimento econômico seja da ordem de $10 \%$, as importações tendem a aumentar em média 5,305\%.

Quanto à dinâmica das exportações e importações dos estados brasileiros, verifica-se que um aumento de $10 \%$ das exportações no período $t-1$ tende a aumentar as exportações no período corrente em $8,384 \%$. Ao passo que, um aumento de $10 \%$ das importações defasadas em um período aumenta, em média, $6,93 \%$ as importações.

De maneira geral, pode-se dizer que a dinâmica das exportações e importa- 
ções apresentam efeitos positivos e significantes, porém esse efeito é menos que proporcional; ou seja, os volumes de exportações e importações defasados afetam de maneira inelástica as exportações e importações no período corrente.

Os coeficientes estimados de $Y_{j t}^{*}$ e $Y_{j t}$, que representam as elasticidades-renda de exportações e importações, respectivamente, são estatisticamente significantes e positivos, nas estimações por System-GMM. Observe que, $\varepsilon_{M, Y}>\varepsilon_{X, Y^{*}}$,ou seja, a elasticidade-enda das importações é superior à elasticidade renda das exportações.

Diante deste resultado, pode-se dizer que no período de 1991 a 2009, para uma variação positiva e proporcional na renda interna e externa, o crescimento das importações relativo às exportações é mais que proporcional e, isto gera uma distorção na balança comercial, restringindo o crescimento econômico dos estados brasileiros. Em outros termos, pode-se dizer que, no período em questão, verifica-se a validade da Lei de Thirlwall.

Esta evidência corrobora aquelas obtidas por Holland, Vieira e Canuto (2004), Martini (2010) e Esteves e Correia (2010) para economias latino-americanas e Caribe ${ }^{20}$. Já Maia e Nunes (2006), embora encontrem evidência de validade da Lei com observações mensais para o período 1990-1998, advertem que esta tendência $\varepsilon_{M, Y}>\varepsilon_{X, Y^{*}}$ se reverte no período posterior, de 1999 a 2005 .

\section{CONSIDERAÇÕES FINAIS}

A possibilidade de se estabelecer relações entre a balança comercial e o crescimento econômico, ao longo das duas últimas décadas, levou este artigo a investigar se a balança comercial é uma restrição ao crescimento econômico dos estados brasileiros.

Para responder a esta indagação, este trabalho buscou evidências da validade da Lei de Thirlwall para a economia dos estados brasileiros no período 1991-2009, a partir da estimação das elasticidades-renda das exportações e importações.

Para estimar essas elasticidades utilizou-se o modelo de painel dinâmico e o estimador System-GMM que, ao corrigir o viés de painel dinâmico quanto os problemas de autocorrelação e heterocedasticidade entre os grupos, e controlar por efeitos fixos, propicia maior robustez aos resultados.

Ao analisar as elasticidades, verificou-se que a elasticidade-renda das importações é superior à elasticidade-renda das exportações. Sendo assim, a partir de um crescimento proporcional na renda interna e externa, pode-se dizer que há um crescimento relativamente maior das importações quando comparado ao das exportações. Tal fato gera uma distorção na balança comercial, restringindo o crescimento econômico dos estados brasileiros.

A limitação imposta pelo balanço de pagamentos é consequência da pauta de

\footnotetext{
${ }^{20}$ Embora Vergolino e Lima (2000) não encontrem uma relação de longo prazo entre PIB e exportações na economia brasileira.
} 
exportações e importações bem como do nível de desenvolvimento dos estados brasileiros. Sendo assim, são necessárias políticas macroeconômicas e industriais que visem, por exemplo, à diversificação dessa pauta e uma maior abertura comercial, através do desenvolvimento tecnológico e da busca por novos mercados para compensar esta restrição do balanço de pagamentos. Caso contrário, conforme os pressupostos do modelo de Thirlwall, a economia dos estados brasileiros estaria então fadada a um crescimento mais lento quando comparado ao crescimento de estados, regiões e/ou países mais desenvolvidos.

\section{REFERENCIAS BIBLIOGRÁFICAS}

Arienti, P. F. F.; Campos, A. C. (2002) "Elasticidades-renda das exportações e importações: o modelo de Thirlwall”. Revista Ensaios (FEE), v. 23, n. 2, p. 787-804.

Arruda, E. F.; Bastos, F. de S.; Guimarães, D. B.; Irffi, G. (2013) "Efeitos assimétricos da abertura comercial sobre o nível de renda dos estados brasileiros”. Economia, v. 14, n. 1B, p. 497-519.

Arellano, M.; Bond, S.(1991) "Some tests of specification for panel data: Monte Carlo evidence and an application to employment equations". Review of Economic Studies, v. 58, p. 277-97.

Arellano, M.; Bover, O. (1995) "Another look at the instrumental-variable estimation of error-components model”. Journal of Econometrics, v. 68, p. 29-52.

Baer, W. (2002) "Neo-Liberalism in Latin America - a return to the past?" Financial Markets and Portfolio Management, v. 16, n. 3.

Blundell, R.; Bond, S. (1998) "Initial conditions and moment restrictions in dynamic panel data models". Journal of Econometrics, v. 87, p. 115-143.

Davidson, P. (1990) “A Lei de Thirlwall”. Revista de Economia Política, v. 10, n.4, p.124-127.

Esteves, L. E.; Correia, F. M. (2012) "Crescimento econômico e Lei de Thirlwall: uma análise para economias latino-americanas”. Análise Econômica, v. 30, n. 57, p. 131-150.

Ferraz, F. C. (2013) "Crise financeira global: impactos na economia brasileira, política econômica e resultados”. Dissertação (Mestrado em economia) - Universidade Federal do Rio de Janeiro.

Fochezatto, A.; Koshiyama, D.; Alencastro, D. (2010) "Testando relações de causalidade entre comércio externo e crescimento econômico em países da américa latina: evidências de dados em painel e séries temporais". Economia, v.11, n.3, p. 597-629.

Hansen, L. (1982) "Large sample properties of generalized method of moments estimators". Econometrica, v. 50, n. 3, p. 1029-54.

Herzer, D. (2011) "Cross-country heterogeneity and the trade-income" . Paper provided by Ibero-America Institute for Economic Research in its series relationship Ibero America Institute for Econ. Research (IAI) Discussion Papers, n. 209, 2011.

Holland, M.; Vieira, F.; Canuto, O. (2004) "Economic growth and the balance-of-payments constraint in Latin America". Investigación Económica, v. 63.

Kim, D. H.; Lin, S. C. (2009) "Trade and growth at different stages of economic development". The Journal of Development Studies, p.1211-1224.

Maia, S. F.; Nunes, D. N. (2006) "Abertura econômica e crescimento: abordagem de Thirlwall para estudos do desempenho da balança comercial brasileira”. Em: Congresso da Sociedade Brasileira de Economia, Administração e Sociologia Rural, Fortaleza, Ceará.

Martini, R. A. (2010) "Crescimento econômico e restrições externas na América Latina e Caribe: Uma análise baseada em dados em painel”. Análise Econômica, n. 54, p. 85-116.

McCombie, J. S. L. (1989) "Thirlwall's law and balance-of-payments-constrained growth: a comment on the debate". Applied Economics, v. 21, p. 9-20.

McCombie, J. S. L.; Thirlwall, A. P. (1994) Economic Growth and the Balance of Payments Constraint. New York: St. Martin's Press. 
Mattoo, A.; Rathindran, R.; Subramanian, A. (2006) "Measuring services trade liberalization and its impact on economic growth: an illustration". Journal of Economic Integration, v. 21, n. 1, p. $64-$ 98.

Nakabashi, L. (2010) "Uma análise dos modelos de Thirlwall ou Solow para e economia brasileira". Economia e Tecnologia, v. 23.

Nakabashi, L. (2012) "Thirlwall ou Solow? Uma análise para a economia brasileira entre 1947 e 2008 " .Economia e Sociedade, v. 21, n. 3 (46), p. 559-584.

Neves, A. C. P.; Lélis, M. T. C. (2007) "Exportações estaduais no Brasil: estimativas para as elasticidades preço e renda". Revista de Economia Política, v. 27, p. 102-135.

Ngozo, T. I. (2006) Openness and Economic Growth: the case of European expansion. Munich Personal RePEc Archive, n. 14.538, 2006.

Pacheco-López, P.; Thirlwall, A. (2006) "Trade liberalization, the income elasticity of demand for imports, and growth in Latin America". Journal of Post Keynesian Economics, v. 29, n. 1.

Pesaran, M. H.; Schuermann, T.; Weiner, S. M. (2004) "Modeling regional interdependencies using a global error-correcting macroeconometric model". Journal of Business and Economic Statistics, v. 22, p. 129-162 e 175-181.

Roodman, D. (2009) "How to do xtabond2: an introduction to "Difference" and "System" GMM in Stata”. Stata Journal, v. 9, n. 1, p. 86-136.

Sargan, J. (1958) "The estimation of economic relationships using instrumental variables". Econometrica, v. 26, n. 3, p. 393-415.

Silva, A. G. da; Vergolino, J. R. O.; Lima, R. C. (2000) "A Lei de Thirlwall e a economia brasileira: uma breve consideração.” Revista Econômica do Nordeste, v. 31, n. especial, p. 852-864.

Thirlwall, A. P. (1979) "The balance of payments constraint as an explanation of international growth rates differences”. Banca Nazionale del Lavoro Quarterly Review, v. 128, p. 45-53.

Thirlwall, A. P. (1986) "Balance of payments constrained growth: a reply". Applied Economics, v. 18, p. 1259-63.

Windmeijer, F. (2005) "A finite sample correction for the variance of linear efficient two-step GMM estimators". Journal of Econometrics, v. 126, p. 25-51. 


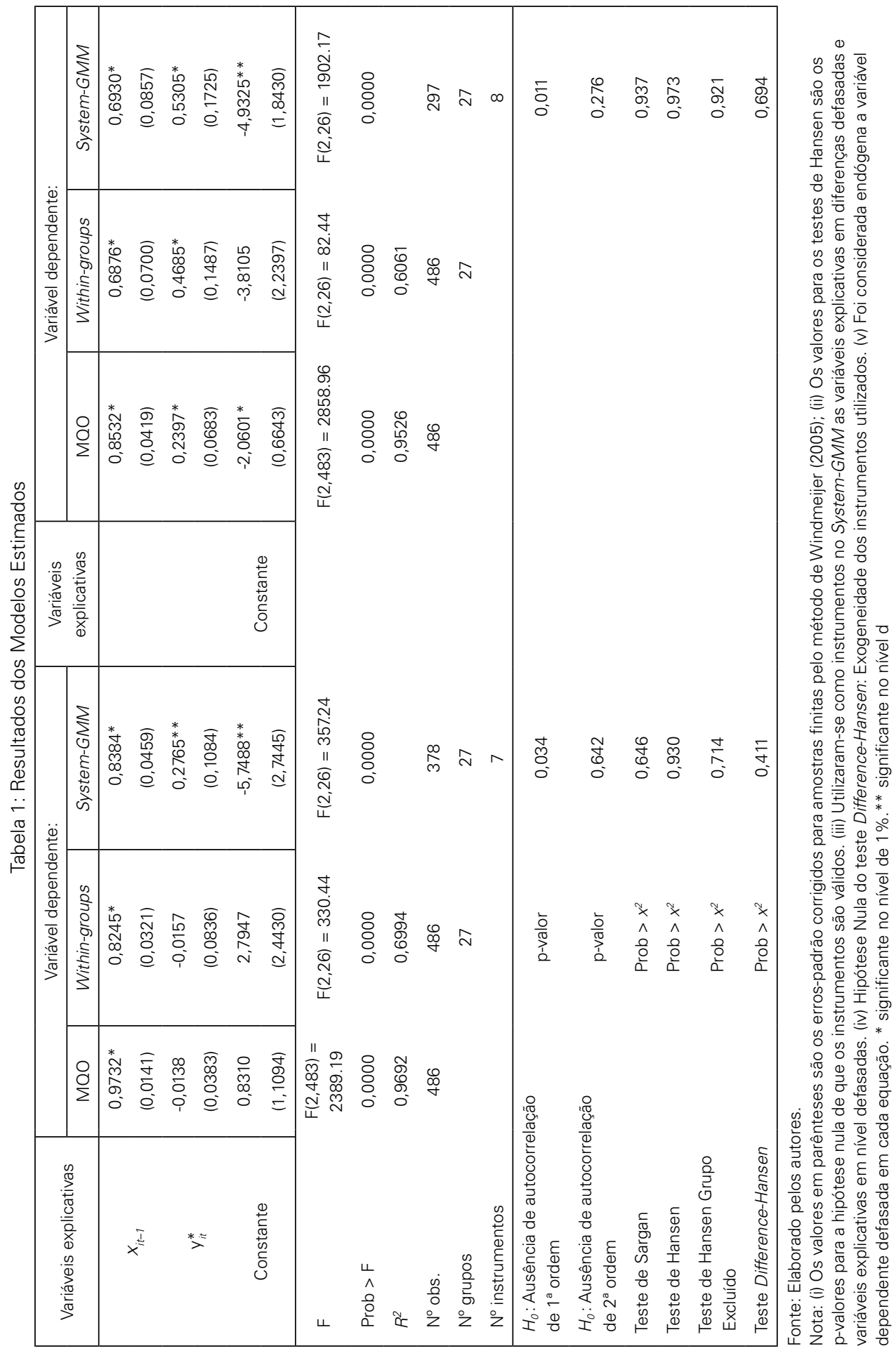

